\title{
Correlates of Low Birth Weight. Psychological Status at Eight to Ten Years of Age
}

\author{
G.WIENER, R.V.Rider, W.C. OpPEL and P.A.HARPER ${ }^{[9]}$ \\ School of Hygiene and Public Health, The Johns Hopkins University, Baltimore, Maryland, USA
}

\begin{abstract}
Extract
Five hundred low birth weight children and 492 full-term infants were seen when approximately 40 weeks of age for a pediatric-neurologic examination. Of these, 822 provided the data upon which this report is based. To each child, when eight to ten years of age, there was administered ten subtests of the Wechsler Intelligence Test for Children (WISC), the Bender Gestalt Test and the Wide Range Reading and Spelling Achievement Test. In addition, observations were recorded regarding speech articulation and complexity of grammar. The number of perseveration instances and indications of possible comprehension aphasia observed during the examinations were recorded. The Verbal IQ, Performance IQ and Full Scale IQ scores, as well as the independently obtained Bender Gestalt score, showed increasing impairment with decreasing birth weight. Approximately twice as large a proportion of low birth weight children as of control children fell into the IQ category (50-79) which is associated with special medical or educational needs. At the ages of six to seven years the results of the Stanford-Binet Test showed an IQ difference between the low birth weight and full-sized groups of 3.4 points $(F=7.77,3$ and $810 \mathrm{df}, \mathrm{p}<0.001)$, whereas the WISG given at the ages of eight to ten years indicated an IQ difference of 4.9 points $(F=10.87,3$ and $810 \mathrm{df}, \mathrm{p}<0.001)$ for the same samples of children. Of the twenty psychological measures used to assess development of those who had been premature, relative impairment on 16 were significantly associated with birth weight and one was nearly so at the 0.05 level of significance. When the effect of the presence of indicators of possible neurologic abnormality was removed by analysis of covariance, the statistical significance of the association with birth weight was reduced for each of the variables measured, and only six of the twenty remained with significant assocation.
\end{abstract}

\section{Speculation}

Future research might profitably consider whether performance by adolescents of low birth weight is relatively impaired in scholastic situations. Also, recent research suggests that a low birth weight occurring in conjunction with long gestational periods, may significantly prejudice intellectual capacity. However, there are little longitudinal data regarding this. 


\section{Introduction}

The purpose of this report is to examine the psychological development at eight to ten years of age of a group of low birth weight ${ }^{1}$ children who have been followed from birth $[1,3,6]$. An earlier report considered the mental status of these subjects when they were six to seven years of age [6]. Several psychological and behavioral defects were observed when race $^{2}$, sex, social class, maternal child-rearing attitudes and personality ratings of the children were controlled. Specifically, low birth weight children showed significantly more impairment than did control children on tests of perceptual-motor skills, abstract reasoning, comprehension, gross motor coordination, speech articulation and intelligence. The impairment was usually greatest in the lowest weight groups. Other evidence suggested that indications of neurologic defect were associated with much of the impairment ascribed to low birth weight.

This paper also presents further evidence of the nature of the differences between low and full birth weight children and an estimate as to whether low birth weight children compensate ('catch up') for their previously noted impairment. It includes data regarding perinatal trauma and neurologic defects observed in infancy to ascertain whether such phenomena are associated with subsequent psychological impairment of low birth weight children.

\section{Population Studied}

Previous reports contain a description of the design of this study $[1,3]$. Five hundred low birth weight children and 492 full-term infants were seen when approximately 40 weeks of age for a pediatric-neurologic examination ${ }^{3}$. The chronologic age at which each low

${ }^{1}$ Low birth weight is defined as less than 2501 grams and is used as an operational definition of prematurity. Control cases (full-term children) are defined as those with a birth weight greater than 2500 grams. This report is not concerned with differences in impairment of low birth weight children with varying gestational periods. Such an analysis is in preparation. It may be noted here that length of gestation does not appear to affect psychologic functioning when this is measured at eight to ten years of age for subjects with birth weights of less than 2500 grams.

${ }^{2}$ Race refers to white and Negro groups and is not meant as an anthropologically or genetically defined variable.

${ }^{3}$ A Gesell developmental examination and a physical examination. birth weight child was examined was corrected to make allowances for the degree of prematurity on this and subsequent examinations. The two groups of subjects were matched for race, season of birth, parity of mother, hospital of birth and socioeconomic status as estimated from census tract data. All children were single born. Data were obtained from the hospital regarding perinatal complications and health of the mother during pregnancy and of the child during the hospitalization period. When those children were three to five years of age, 900 were located and examined using the Stanford-Binet Intelligence Test, Form L.

A third examination was conducted when subjects were six to seven years of age. At that time, the Stanford-Binet Test, Form L, was repeated, together with other procedures [6]. Social class and maternal attitudes and practices were evaluated by social workers who interviewed each child's parent or guardian.

Data to be presented here concern the fourth round of examinations when the children were eight to ten years of age. Eight hundred and forty-one children of the original 992 were located. Of these, 822 provided the data upon which this report is based. The other 19 subjects were excluded from this report because of severe sensory or gross motor disturbance or an IQ of less than 50. Sixteen of these excluded cases were of low birth weight; three were control cases. Analysis of data not presented here indicated that the previous intelligence test scores of the nonlocated children were not significantly different from the 822 children who are the subject of this report.

\section{Method}

Each child was administered ten subtests of the Wechsler Intelligence Test for Children (WISG), the Bender Gestalt Test and the Wide Range Reading and Spelling Achievement Test. In addition, observations were recorded regarding speech articulation and complexity of grammar. The number of perseveration instances and indications of possible comprehension aphasia observed during the examinations were recorded. Children's parents (or guardians) were again interviewed by social workers and rated for a variety of social class and attitudinal variables.

With but few exceptions, the social worker and psychologist who collected data were unaware of a subject's past history or prior test performances. After all children had been examined, raters scored Bender Gestalt reproductions according to a scheme designed by one of the authors [5]. This procedure insured that Bender Gestalt scores were free of any influence from other test results, physical appearance, knowledge of past history or any other bias. Each Bender protocol 
was scored for instances of perseveration, separation of figures, inability to make acute angles or sine curves, crudeness of motor coordination and gross distortion of Gestalt perception.

\section{Results}

\section{Differences Between Birth Weight Groups}

Sixteen of the twenty measures used indicated significant differences between birth weight groups. Data presented in table I consider only the Wechsler Intelligence Test for Children and Bender Gestalt Test scores.

The Verbal IQ, Performance IQ and Full Scale IQ scores, as well as the independently obtained Bender Gestalt score, showed increasing impairment with decreasing birth weight. These findings were similar for Negro and white subjects. Racial differences were highly significant, but a discussion of these is beyond the scope of this report except to observe that these differences have tended to increase with age and are assumed to be influenced by environment. It is of interest, however, that Negro children were no more impaired than white children as a function of birth weight. Although social class differences (as estimated from census tract data) were controlled by initial matching of subjects when the study began, further controls for such variables were provided by using additional data obtained when subjects were eight to ten years of age. These data, obtained by social workers, were factor analyzed and ten resulting measures were simultaneously covaried ${ }^{4}$. The $\mathrm{F}$ scores of table I are based on this control, as well as race via analysis of variance.

The birth weight differences in mean intelligence test scores shown in table I are not sufficient to make a clinical or educational prediction for any given child; however, when the impaired extreme of the distribution is examined (IQ 50 to 79) large differences exist between groups. Approximately twice as large a proportion of low birth weight children as of control children fall into the IQ category (50 to 79) which is associated with special medical or educational needs.

To the extent that groups of children differed significantly on each of three psychological variables (Verbal IQ, Performance IQ, Bender Gestalt), it seemed likely that a better estimate of the true difference between birth weight groups would consist of a weighted combination of the three variables. A discriminant function statistic was calculated to assign weights to each of the three variables in order to maximally separate groups. These weights were then multiplied by sub-

${ }^{4}$ The analysis of data concerning social class and maternal attitudes will be reported elsewhere. ject's score for each of the three variables, and a new variable was produced.

As shown in table II, subjects were grouped into sextiles which reflect composite 'psychological efficiency' ${ }^{5}$ or rank as estimated by this single 'new' variable. Sextiles were prepared separately for each race. The lowest (6th) sextile, for example, may be interpreted as those children who have the most unfavorable scores on the three measures weighted to maximally separate the birth weight groups ${ }^{6}$. This weighted combination of psychological test scores does discriminate between birth weight groups; $p<0.001$ for white subjects, for Negro subjects and for white and Negro subjects. It is worth pointing out that the information in table II is also a reminder that there is much overlap between the birth weight groups. In terms of performance, many low birth weight children cannot be differentiated from high birth weight children even when subjected to a wide variety of tests.

Changes in Impairment of Low Birth Weight Children ïith Age

The question considered here is whether the difference between birth weight groups changes as prematures grow older. Do prematures 'catch up' as opportunities for compensation via learning experiences increase? This question is difficult to answer because different ages of childhood are related to quite different tests which measure different aspects of mental ability.

Changes between groups might be judged by the changes in measures of significance if degrees of freedom remain constant. Table III presents some relevant data.

At the ages of six to seven years, the Stanford-Binet showed an IQ difference between the low birth weight and full-sized groups of 3.4 points, $F=7.77,3$ and 810 degrees of freedom (df), $p<0.001$, whereas the WISC at the ages of eight to ten years indicated an IQ difference of 4.9 points $(F=10.87,3$ and $810 \mathrm{df}$, $\mathrm{p}<0.001)$ for the same samples of children. These measures suggest that prematures as a group have not caught up at the ages of eight to ten years to the extent that low birth weight children are relatively impaired on both tests.

5 'Psychological efficiency' is not meant to be comparable with other uses of this term which may appear in the literature. Operationally, it is defined simply as relatively good performances on the WISC and Bender Gestalt Tests.

${ }^{6}$ It should be noted that this maximizing procedure would not produce as wide a dispersion for subsequent samples. However, to the extent that separate groups of white and Negro low birth weight children are comparably impaired, the obtained dispersion is considered partially replicated. 
Table I. Psychological test scores by birth weight and race $^{1}$ when subjects were eight to ten years of age

\begin{tabular}{|c|c|c|c|c|c|c|c|c|}
\hline & \multicolumn{6}{|c|}{ Birth weight } & \multirow{3}{*}{$\begin{array}{l}\text { F for } \\
\text { birth } \\
\text { weight }^{2} \\
(2 \text { and } \\
800 \text { df })^{4}\end{array}$} & \multirow{3}{*}{$\begin{array}{l}\text { Pooled } \\
\text { standard } \\
\text { deviation }\end{array}$} \\
\hline & \multicolumn{2}{|c|}{$<2000 \mathrm{~g}$} & \multicolumn{2}{|c|}{$2000-2500 \mathrm{~g}$} & \multicolumn{2}{|c|}{$>2500 \mathrm{~g}$} & & \\
\hline & White & Negro & White & Negro & White & Negro & & \\
\hline \multicolumn{9}{|l|}{ WISC mean score } \\
\hline Verbal IQ & 95.9 & 83.7 & 97.8 & 85.9 & 102.0 & 89.6 & 17.70 & 13.14 \\
\hline Performance IQ & 92.3 & 85.5 & 100.8 & 87.9 & 106.0 & 92.3 & 19.54 & 14.68 \\
\hline Full scale IQ & 96.9 & 83.1 & 99.3 & 85.5 & 105.0 & 89.9 & 22.94 & 13.65 \\
\hline \multicolumn{9}{|l|}{ Bender Gestalt } \\
\hline mean score ${ }^{3}$ & 14.4 & 19.3 & 14.1 & 17.6 & 11.9 & 17.0 & 16.21 & 5.23 \\
\hline Total cases & 32 & 83 & 125 & 177 & 167 & 238 & & \\
\hline \multicolumn{9}{|c|}{ Number with WISC full } \\
\hline scale IQ 50-79 & 4 & 32 & 12 & 61 & 8 & 46 & & \\
\hline & 12.5 & 38.6 & 9.6 & 34.5 & 4.8 & 19.3 & & \\
\hline Mean corrected age & 8.9 & 8.8 & 8.8 & 8.8 & 8.8 & 8.8 & 1.00 & 0.39 \\
\hline
\end{tabular}

1 Negro-white differences are highly significant, but a discussion of this is beyond the scope of this report.

${ }^{2} \mathrm{~F}$ values shown for psychological measures are significant $(\mathrm{p}<0.001)$. Mean age is not different for any of the groups.

${ }^{3}$ Higher scores indicate a greater degree of impairment.

4 This analysis examines birth weight (2 degrees of freedom, df) controlling for sex (not shown in table) and race, and covarying 10 social factors, reducing the remaining degrees of freedom to 800 .

Table II. Number and percentage of cases by sextiles of 'psychological efficiency' and birth weight using a weighted combination of three psychological test scores $^{1}$

\begin{tabular}{|c|c|c|c|c|c|c|c|c|c|c|c|c|}
\hline \multirow{3}{*}{$\begin{array}{l}\text { Composite } \\
\text { 'psychological } \\
\text { efficiency' } \\
\text { sextile }\end{array}$} & \multicolumn{4}{|c|}{ White } & \multicolumn{4}{|c|}{ Negro } & \multicolumn{4}{|c|}{ Total } \\
\hline & \multicolumn{2}{|c|}{$<2501 \mathrm{~g}$} & \multicolumn{2}{|c|}{$>2500 \mathrm{~g}$} & \multicolumn{2}{|c|}{$<2501 \mathrm{~g}$} & \multicolumn{2}{|r|}{$>2500 \mathrm{~g}$} & \multicolumn{2}{|c|}{$<2501 \mathrm{~g}$} & \multicolumn{2}{|c|}{$>2500 \mathrm{~g}$} \\
\hline & $\mathrm{N}$ & $\%$ & $\mathrm{~N}$ & $\%$ & $\mathrm{~N}$ & $\%$ & $\mathrm{~N}$ & $\%$ & $\mathrm{~N}$ & $\%$ & $\mathrm{~N}$ & $\%$ \\
\hline 1st (high) & 13 & 8.3 & 41 & 24.6 & 37 & 14.2 & 46 & 19.3 & 50 & 12.0 & 87 & 21.5 \\
\hline 2nd & 27 & 17.2 & 27 & 16.2 & 35 & 13.5 & 48 & 20.2 & 62 & 14.9 & 75 & 18.5 \\
\hline $3 r d$ & 25 & 15.9 & 29 & 17.4 & 38 & 14.6 & 45 & 18.9 & 63 & 15.1 & 74 & 18.3 \\
\hline 4 th & 31 & 19.7 & 23 & 13.8 & 44 & 16.9 & 39 & 16.4 & 75 & 18.0 & 62 & 15.3 \\
\hline 5 th & 25 & 15.9 & 29 & 17.4 & 48 & 18.5 & 35 & 14.7 & 73 & 17.5 & 64 & 15.8 \\
\hline 6 th (low) & 36 & 22.9 & 18 & 10.8 & 58 & 22.3 & 25 & 10.5 & 94 & 22.5 & 43 & 10.6 \\
\hline Total & 157 & 99.9 & 167 & 100.2 & 260 & 100.0 & 238 & 100.0 & 417 & 100.0 & 405 & 100.0 \\
\hline
\end{tabular}

1 The WISC Verbal and Performance IQ and the Bender Gestalt constituted the three variables combined to form a single index. The significance of the separation between birth weight groups may be expressed as follows:

White subjects. $\mathrm{X}^{2}=16.40,1 \mathrm{df}, \mathrm{p}<0.001$.

Negro subjects. $X^{2}=20.70,1 \mathrm{df}, p<0.001$.

Both groups. $\quad \mathrm{X}^{2}=37.10,2 \mathrm{df}, \mathrm{p}<0.001$.

8 Pediat. Res., Vol. 2, No. 2 (1968) 
Table III. Intelligence test scores for children at the ages of six to seven years and eight to ten years by birth weight ${ }^{1}$

\begin{tabular}{|c|c|c|c|c|c|c|c|}
\hline \multirow[t]{3}{*}{ Examination } & \multicolumn{6}{|c|}{ Birth weight groups } & \multirow{3}{*}{$\begin{array}{l}\mathrm{F}(3 \text { and } \\
810 \mathrm{df})\end{array}$} \\
\hline & \multicolumn{3}{|c|}{ Low birth weight } & \multicolumn{3}{|c|}{ All subjects } & \\
\hline & $<1501 \mathrm{~g}$ & $\begin{array}{l}1501- \\
2000 \mathrm{~g}\end{array}$ & $\begin{array}{l}2001- \\
2500 \mathrm{~g}\end{array}$ & $<2501 \mathrm{~g}$ & $>2500 \mathrm{~g}$ & $\begin{array}{l}\text { Differ- } \\
\text { ence }\end{array}$ & \\
\hline WISC, ages 8-10 & 84.7 & 88.5 & 90.8 & 89.8 & 94.7 & 4.9 & 10.84 \\
\hline Number & 41 & 74 & 302 & 417 & 405 & & $(\mathrm{p}<0.001)$ \\
\hline $\begin{array}{l}\text { Stanford-Binet, Form L, } \\
\text { ages } 6-7\end{array}$ & 88.9 & 90.6 & 93.0 & 92.2 & 95.6 & 3.4 & 7.77 \\
\hline Number & 44 & 68 & 301 & 413 & 409 & & $(p<0.001)$ \\
\hline
\end{tabular}

1 This analysis controlled for three levels of social class as determined by an index consisting of parental education, income, housing and employment. F ratios for the interaction of three levels of social class with four levels of birth weight were 1.34 and 0.60 (6 and $810 \mathrm{df})$ for the Stanford-Binet test and WISC respectively. These are not significant.

Table IV. Incidence of indicators of possible neurologic abnormalities by birth weight

\begin{tabular}{|c|c|c|c|c|c|c|c|c|}
\hline \multirow[t]{3}{*}{ Variable } & \multicolumn{6}{|c|}{ Birth weight } & & \\
\hline & \multicolumn{2}{|c|}{$<2000 \mathrm{~g}$} & \multicolumn{2}{|c|}{$2000-2500 \mathrm{~g}$} & \multicolumn{2}{|c|}{$>2500 \mathrm{~g}$} & \multicolumn{2}{|r|}{$\mathrm{X}^{21}$} \\
\hline & No. & $\%$ & No. & $\%$ & No. & $\%$ & $(4 \mathrm{df})$ & $\mathrm{p}$ \\
\hline $\begin{array}{l}\text { Total number of subjects } \\
\text { Pathology in mother or early } \\
\text { infancy }\end{array}$ & 115 & & 302 & & 405 & & & \\
\hline 1. Clinical correlates & 29 & 25.2 & 35 & 11.6 & 65 & 16.1 & 24.9 & $<0.001$ \\
\hline 2. Lues (mother) & 13 & 11.3 & 10 & 3.3 & 25 & 6.2 & 8.2 & $<0.10$ \\
\hline 3. Bleeding during pregnancy & 36 & 31.3 & 40 & 13.3 & 55 & 13.6 & 22.3 & $<0.001$ \\
\hline 4. Possible mechanical trauma & 35 & 30.4 & 60 & 19.9 & 68 & 16.8 & 10.9 & $<0.05$ \\
\hline 5. Oxygen deprivation & 21 & 18.3 & 13 & 4.3 & 4 & 1.0 & 73.6 & $<0.001$ \\
\hline 6. Abnormal muscle tone & 14 & 12.2 & 10 & 3.3 & 4 & 1.0 & 42.4 & $<0.001$ \\
\hline 7. Illness & 27 & 23.5 & 14 & 4.6 & 12 & 3.0 & 68.0 & $<0.001$ \\
\hline 8. Jaundice & 50 & 43.5 & 103 & 34.1 & 106 & 26.2 & 14.0 & $<0.01$ \\
\hline 9. Convulsive disorders (child) & 17 & 14.8 & 29 & 9.6 & 45 & 11.1 & 3.2 & n.s. \\
\hline \multicolumn{9}{|l|}{$\begin{array}{l}\text { Neurologic abnormality noted } \\
\text { during } 40 \text {-week examination }\end{array}$} \\
\hline 10. Head & 7 & 6.1 & 8 & 2.7 & 2 & 0.5 & 15.0 & $<0.005$ \\
\hline 11. Arms and hands & 96 & 83.5 & 226 & 74.8 & 235 & 58.0 & 41.2 & $<0.001$ \\
\hline 12. Strabismus & 18 & 15.7 & 27 & 8.9 & 19 & 4.7 & 17.4 & $<0.005$ \\
\hline 13. Other eye disorders & 4 & 3.5 & 3 & 1.0 & 0 & 0 & 12.5 & $<0.025$ \\
\hline 14. Legs and feet & 53 & 46.1 & 110 & 36.4 & 110 & 27.2 & 19.0 & $<0.001$ \\
\hline 15. Postural disturbances & 20 & 17.4 & 32 & 10.6 & 30 & 7.4 & 10.3 & $<0.05$ \\
\hline 16. Abnormal locomotion & 13 & 11.3 & 28 & 9.3 & 32 & 7.9 & 5.7 & n.s. \\
\hline 17. Abnormal muscle tone & 25 & 21.7 & 34 & 11.3 & 26 & 6.4 & 22.2 & $<0.001$ \\
\hline 18. Substitutive patterns & 12 & 20.4 & 50 & 16.6 & 41 & 10.1 & 8.5 & $<0.10$ \\
\hline 19. Reflex disturbances & 59 & 51.3 & 139 & 46.0 & 119 & 29.4 & 28.9 & $<0.001$ \\
\hline
\end{tabular}

1 Based on $\mathrm{X}^{2}$ tests made separately for Negro and white subjects. $\mathrm{X}^{2}$ scores were added, as were degrees of freedom. 
Table $V$. Mean number of indicators of possible neurologic abnormality by race and birth weight ${ }^{1}$

\begin{tabular}{|c|c|c|c|c|c|c|}
\hline \multirow[t]{2}{*}{ Race } & \multicolumn{2}{|c|}{$<2000 \mathrm{~g}$} & \multicolumn{2}{|c|}{$2000-2500 \mathrm{~g}$} & \multicolumn{2}{|c|}{$>2500 \mathrm{~g}$} \\
\hline & $\begin{array}{l}\text { Mean No. } \\
\text { abnormal- } \\
\text { ities }\end{array}$ & $\begin{array}{l}\text { No. of } \\
\text { subjects }\end{array}$ & $\begin{array}{l}\text { Mean No. } \\
\text { abnormal- } \\
\text { ities }\end{array}$ & $\begin{array}{l}\text { No. of } \\
\text { subjects }\end{array}$ & $\begin{array}{l}\text { Mean No. } \\
\text { abnormal- } \\
\text { ities }\end{array}$ & $\begin{array}{l}\text { No. of } \\
\text { subjects }\end{array}$ \\
\hline White & 6.59 & 32 & 4.69 & 125 & 3.32 & 167 \\
\hline Negro & 6.92 & 83 & 4.40 & 177 & 3.33 & 238 \\
\hline
\end{tabular}

${ }^{1} \mathrm{~N}=822 ; \mathrm{F}$ (for birth weight) $=55.72,2$ and $816 \mathrm{df}, \mathrm{p}<0.001$. Pooled standard deviation is 3.19. F ratio between racial groups is not significant. For both white and Negro subjects, larger prematures are significantly different from controls.

An Index of the Neurologic Correlates of Low Birth Weight As previously noted, data were obtained for each of the 992 cases from hospital records regarding conditions which suggest pathology or potential pathology in the mother, or in the infant shortly after birth, and from a neurologic evaluation of the 40 -week-old infants. These variables are:

\section{A. Maternal disorders and perinatal pathology}

1. Glinical correlates (hypertensive disorders, preeclampsia, eclampsia)

2. Lues in mother

3. Bleeding during pregnancy

4. Possible mechanical trauma as indicated by mid or high forceps, breech delivery, cesarean section

5. Oxygen deprivation as indicated by a notation of cyanosis or gasping

6. Abnormal muscle tone (hyper- or hypotonia)

7. Illnesses such as erythroblastosis and severe diarrhea (excluding jaundice)

8. Jaundice

9. Convulsive disorders

B. Neurologic abnormalities noted during the 40-wrek examination?

10. Head (tilting, sagging)

11. Arms and hands (adduction, abduction)

12. Strabismus

13. Other eye disorders

14. Legs and feet (scissoring, withdrawal in standing)

15. Postural disturbances (abnormal tonic neck reflex)

16. Abnormal locomotion (dragging leg in crawling)

17. Abnormal muscle tone (tremor, rigidity)

18. Substitutive patterns

19. Reflex disturbance

${ }^{7}$ All neurological examinations at 40 weeks of age were done by one examiner, Dr. HrLda KNobloch.
The incidence of each of these indicators of possible pathology is compared for three birth weight groups in table IV.

Data in table IV show that 15 of the 19 indicators were found significantly $(p<0.05)$ more frequently in low birth weight children. Apparently, decreasing birth weight is associated with a greater incidence of these indicators of pathology or potential pathology. It is suggested that low birth weight children have an increased risk of neurologic pathology; this risk increases as birth weight decreases.

An attempt was made to study the combined effect of the 19 indicators shown in table IV by giving each child a score equal to the number of these indicators which were in his record. Since table IV shows that these individual indicators of potential pathology are found more frequently among low birth weight children, it was hypothesized that a combined index obtained by counting the number of such indicators per child should also give a score that would be inversely related to birth weight. It is emphasized that this score merely provides an operational definition of possible neurologic abnormality and is not an established indicator of such abnormality. Table $V$ presents an analysis of the frequency of these scores for white and Negro subjects and for birth weight groups.

The findings are highly significant for each of the races; low birth weight children have more indicators of possible neurologic abnormality. It is of interest that the greater psychologic handicap of Negro subjects shown in tables $I$ and II is not associated with a greater incidence of perinatal and neurologic abnormalities $^{8}$.

${ }^{8}$ The differences between white and Negro children for each birth weight group are frequently large and highly significant. It is presumed that such differences are due to cultural or other environmental factors. A discussion of this is beyond the scope of this report. 
Data in tables IV and V refer only to the frequency of indicators or defects and not to severity. A better scale would consider both concepts. Further, the scores analyzed in table $\mathrm{V}$ consider each variable equally important. This is not the case. Statistical procedures for weighting variables are applicable with confidence only when a given variable is scaled to give a continuous, normal distribution.

Data in table VI illustrate a further attempt to ascertain whether the mental impairment of low birth weight children is due, to an important extent, to associated neurologic abnormalities as suggested in table IV.

Table VI. F ratios for twenty psychological measures comparing the three birth weight groups shown in table $V$

\begin{tabular}{|c|c|c|}
\hline Psychological measure & 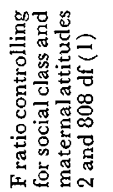 & 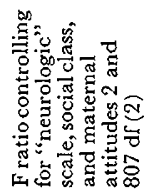 \\
\hline
\end{tabular}

WISC subtests

1. Information $\quad 6.36 \quad 3.40$

2. Comprehension $\quad 4.56 \quad 1.27$

3. Arithmetic $\quad 5.86 \quad 4.83$

4. Similarities $\quad 3.64 \quad 0.63$

5. Digit span $\quad 4.11 \quad 1.11$

6. Vocabulary $\quad 4.74 \quad 3.55$

7. Picture completion $\quad 3.65 \quad 2.20$

$\begin{array}{lll}\text { 8. Block design } & 5.57 & 2.16\end{array}$

9. Object assembly $\quad 6.93 \quad 1.90$

10. Digit symbol $\quad 5.97 \quad 2.24$

Observations

1. Comprehension difficulty $\quad 7.33 \quad 4.82$

2. Perseveration trend $\quad 0.94 \quad 1.16$

3. Concrete thinking $\quad 6.66 \quad 2.29$

4. Speech distortions $\quad 4.05 \quad 3.87$

5. Speech substitutions $\quad 3.12 \quad 1.83$

6. Speech omissions $\quad 4.35 \quad 3.87$

7. Sentencestructure: complexity $1.65 \quad 1.56$

8. Tenses: complexity $\quad 0.610 .38$

WRAT achievement test

$\begin{array}{lll}\text { 1. Reading } & 3.46 & 2.11 \\ 2 . \text { Spelling } & 2.98 & 2.01\end{array}$

$\mathrm{N}=822$. Design of factorial analysis controlled for race and sex. For 2 and $800 \mathrm{df}, \mathrm{F}$ ratios of 3.00 and 4.62 are significant at the 0.05 and 0.01 level of confidence, respectively.
It can be noted that of the twenty psychological measures used to assess development of prematures, the ratings on 16 were significantly associated with birth weight and one was nearly so at the 0.05 level of significance (see column 1 of table VI). When the effect of the presence of indicators of possible neurologic abnormality was removed by analysis of covariance, the statistical significance of the association with birth weight was reduced for each of the variables measured, and only six of the twenty remained with significant association (see column 2 of table VI).

The perinatal and neurologic data, which we have called 'indicators', are to some extent unreliable. Unfortunately, no estimate of this is available. Also, combining these data into a 'scale' has unavoidable statistical flaws previously alluded to. Each of these two deficiencies may be expected to have decreased the predictive value of the 'neurologic' indicator scale score, and it is probable that their removal would strengthen the conclusion that low birth weight is associated with impaired performance in a wide variety of psychological measures largely to the extent that a neurologic disturbance is present ${ }^{9}$.

\section{Comments}

Low birth weight is associated with impaired mental development in eight- to ten-year-old children. This finding is in accordance with earlier findings from this longitudinal study and with the weight of evidence from other studies [2, 4]. This impairment is not secondary to correlated socioeconomic factors or to the quality of 'mothering'. Such factors were controlled by the original design of the study and by the use of the statistical techniques of analysis of variance and covariance. Further data, not presented here, provide evidence that mental impairment is not secondary to behavioral disturbances, such as hyperactivity, frequently shown by brain damaged children. The data show that the noted mental impairment is associated with an index of possible neurologic defect. Data presented here do not suggest specific diagnostic clues for clinical prediction of impaired mental development.

'Catching up' has not occurred, if one is to judge this by standard tests of intelligence. Although some children do compensate, others show increasing mental impairment. Rather, low birth weight children as a group

${ }^{9}$ It would be desirable to correlate specific 'neurologic' data with later psychologic performance and thereby suggest patterns of possible relations. However, the nonscalar and nonnormal nature of each of the 19 'neurologic' indicators precludes this correlational approach. 
do not appear to have caught up to full-term children to the extent that they can be determined by the measures utilized in this study.

An earlier report from this longitudinal study indicated that the Stanford-Binet Intelligence Test score was not as significant a discriminator of low birth weight groups at the ages of six to eight years as was the Bender Gestalt Test or other psychological measures [6]. The $\mathrm{F}$ ratios in table I suggest, however, that the WISC scores are a better discriminator of birth weight groups at ages eight to ten years than is the Bender Gestalt at this age. Such seemingly discrepant findings reflect the fact that the two intelligence tests are notably different and demand different types of mental activity.

Children of lower classes or of the Negro race are not relatively more impaired as a function of low birth weight. The effects of birth weight are similar in each social class group and in each race. There is no evidence of a statistical interaction between low birth weight and social class or race. Similar findings and statistical tests of this observation were presented in an earlier report [6].

Some clinical workers have suggested that the presence of brain damage can be diagnosed in part by 'scatter' or by inconsistent performances. It follows that children of low birth weight groups should show more 'scatter' on test scores than controls since they have a greater risk of brain injury. In order to test this hypothesis, the variability of each child's scores on the ten Wechsler subtests was estimated by computing a standard deviation; birth weight groups did not differ significantly with regard to this measure of variability (data not shown here). It appears that 'scatter' in itself is not a meaningful diagnostic device with respect to the minimal defect with which this report is concerned and with regard to the ages and measures used. A possible explanation for this observation is that those processes affected by minimal brain damage may be noted in any of the WISC subtests.

Data in table VI suggest, perhaps surprisingly, that reading and spelling achievement scores at best only slightly discriminate birth weight groups, whereas many other measures, including arithmetic, are better. School achievement data were obtained from thirdand fourth-grade children and yielded similar findings (not shown here). Possibly scholastic achievement as measured by tests of reading and spelling through the age of ten years is not as remarkably affected as are other measures because of the age of the children; it is possible that such impairment may be noted at a later age.

The final follow-up of this longitudinal study concerned scholastic achievement of subjects when they were thirteen years of age. Preliminary analysis indi- cates the scholastic achievement of the thirteen-yearold expremature is significantly impaired. These data will be presented in a later report.

\section{Summary}

Four hundred and seventeen low birth weight children and 405 full-term children were examined at the ages of eight to ten years using a variety of psychological measures including the Wechsler Intelligence Test for Children, the Bender Gestalt Test and the Wide Range Achievement Test. In addition, data were available for the socioeconomic classes of the families and childrearing practices of the mothers. Perinatal information was obtained from hospital records and neurologic data from an examination performed when subjects were approximately 40 weeks of age.

Low birth weight children are impaired on a wide variety of psychological factors, including ten subtests of the Wechsler Intelligence Test for Children. Such impairment is not due to social class or to maternal attitudes and practices. The degree of impairment is greatest for children with smaller birth weight. Lower birth weight children appear to have a greater risk of impaired mental performance largely because of associated indications of neurologic defect. When intelligence test data for eight- to ten-year-old-children are compared with the data obtained when these children were six to seven years of age, it appears that "catching up' has not occurred. It should be emphasized that the impaired performance represents a relative group trend. Most low birth weight children are not impaired, and the overlap between birth weight groups may be more clinically meaningful than the differences between groups. However, low birth weight, when associated with indicators of neurologic pathology, constitutes a higher risk category.

\section{References and Notes}

1. HARPer, P.A.; Frscher, L.K. and Rider, R.V.: Neurological and intellectual status of prematures at three to five years of age. J. Pediat. 55: 679 (1959).

2. Harper, P.A. and Wiener, G.: Sequelae of low birth weight. Ann. Rev. Med. 16: 405 (1965).

3. KNobloch, H.; Rider, R.V.; Harper, P.A. and Pasamanick, B.: Neuropsychiatric sequelae of prematurity. J. amer. med. Ass. 161: 581 (1956).

4. Wiener, G.: Psychological correlates of premature birth: A review. J. nerv. ment. Dis. 134: 129 (1962).

5. Wiener, G.: The Bender Gestalt test as a predictor of minimal brain damage in children eight to ten years of age. J. nerv. ment. Dis., 143: 275 (1966). 
6. Wiener, G.; Rider, R.V.; Oppel, W. C.; Fischer, L.K. and HARPER, P.A.: Correlates of low birth weight: psychological status at six to seven years of age. J. Pediat. 35: 434 (1965).

7. The authors wish to express their gratitude to Doctors Dean Clyde, Gharles E. Hall, and Elliot M. CRAMER of the Biostatistics Department of the University of Miami for their invaluable statistical advice, and for generously making their computer programs available. The authors are also deeply indebted to Mr. Robert Burow, Mrs. ANN WAGNer, and Mrs. Donna Rrodes of the Johns Hopkins Medical Computing Center (NIH Grant No. FR00004) for their cooperation and assistance in all stages of programming and computer use. They also wish to express their appreciation to the Baltimore Gity Board of School Commissioners and to the Department of Catholic Education of the Archdiocese of Baltimore for the valuable contribution of many persons on their staffs.

8. This study was supported by funds made available by the Children's Bureau, US Department of Health, Education and Welfare, and by the Thomas Wilson Sanitarium.

9. Requests for reprints should be addressed to: Dr. P.A.HARPER, School of Hygiene and Public Health, The Johns Hopkins University, 615 North Wolfe Street, Baltimore, Md. 21205 (USA). 